\title{
Correction to: One decade of glioblastoma multiforme surgery in 342 elderly patients: what have we learned?
}

\author{
Dieter Henrik Heiland ${ }^{1,4}(\mathbb{D})$. Gerrit Haaker ${ }^{1,4}$. Ralf Watzlawick ${ }^{1,4}$. Daniel Delev ${ }^{1,4}$. Waseem Masalha ${ }^{1,4}$. \\ Pamela Franco $^{1,4}$ - Marcia Machein ${ }^{1,4}$. Ori Staszewski ${ }^{2,4}$. Oliver Oelhke ${ }^{3,4} \cdot$ Nils Henrik Nicolay $^{3,4} \cdot$ Oliver Schnell ${ }^{1,4}$
}

Published online: 10 September 2018

(c) Springer Science+Business Media, LLC, part of Springer Nature 2018

Correction to: Journal of Neuro-Oncology

https://doi.org/10.1007/s11060-018-2964-8

There was a typo in the third author's name in the initial online publication. The original article has been corrected.

The original article can be found online at https://doi.org/10.1007/ s11060-018-2964-8.

Dieter Henrik Heiland

dieter.henrik.heiland@uniklinik-freiburg.de

1 Department of Neurosurgery, Medical Center, University of Freiburg, Breisacher Straße 64, 79106 Freiburg, Germany

2 Institute of Neuropathology, Medical Center, University of Freiburg, Freiburg, Germany

3 Radiation Clinic, Medical Center, University of Freiburg, Freiburg, Germany

4 Faculty of Medicine, University of Freiburg, Freiburg, Germany 